\title{
EI círculo en la relación espacio y cuerpo. Foto-ensayo a partir de Isidro Blasco y el método BAPNE
}

\author{
The circle in the relationship between space and body. \\ Photo-essay based on Isidro Blasco and the BAPNE method
}

\author{
Amparo Alonso-SAnZ \\ Universidad de Valencia \\ amparoas@gmail.com \\ Francisco J. Romero-NARANJO \\ Universidad de Valencia \\ bodypercussion@gmail.com
}

Recibido: 12 de marzo de 2013

Aprobado: 1 de junio de 2015

\section{Resumen}

En el presente artículo se muestra un estudio visual sobre el espacio educativo universitario en el que se desarrollan enseñanzas sobre percusión corporal. Como marco metodológico se escoge la Investigación Educativa Basada en las Artes Visuales empleándose la obra de un artista como referente conceptual y metodológico. La investigación queda marcada tanto por la referencia visual a la obra de Isidro Blasco especialmente con la obra "Shanghai planet 2009"-; como por los paralelismos establecidos entre el objeto de estudio de esta investigación -el análisis espacial- y los focos de interés desvelados por los críticos de arte respecto a la obra de este artista. Mediante un discurso visual formado por 7 fotocollages se visualiza la relación entre cuerpo y espacio educativo en la disposición básica de aprendizaje circular. Las construcciones visuales a modo de fotocollage y su carga estética nos aproximan a la intimidad del espacio educativo, al modo en que se distribuye al alumnado en el aula de música, la materialización de las relaciones interpersonales, los volúmenes ocupados y vacíos.

Palabras clave: Investigación Educativa Basada en las Artes Visuales, Isidro Blasco, percusión corporal, método BAPNE, foto-ensayo.

Alonso-Sanz, A., Romero-Naranjo, F.J. (2015): El círculo en la relación espacio y cuerpo. Foto-ensayo a partir de Isidro Blasco y el método BAPNE. Arte, Individuo y Sociedad, 27(3) 359-374 


\begin{abstract}
This article demonstrates a visual study on the educational space in which the teaching of body percussion is carried out in universities. The methodological framework is chosen by the Visual Arts Based Educational Research, using the work of an artist as a conceptual and methodological model. The research remains notable (1) due to the theoretical reference to the BAPNE method, (2) due to the visual reference to the work of Isidro Blasco - especially with the piece "Shanghai Planet 2009" - ;(3) due to the parallelisms established between the object of study in this investigation -the spatial analysis- and the focuses of interest revealed by the art critics in relation to the work of this artist. By means of a visual speech formed with 7 photo-collages the relationship between body and educational space is visualized in the basic disposition of circular learning. The visual constructions by way of photo-collage and their aesthetic charge brings us closer to the intimacy of the educational space, in the style in which it is distributed to the students in the music classroom, the materialization of interpersonal relationships, the occupied and empty volumes. Keywords: Visual Arts Based Educational Research, Isidro Blasco, body percussion, BAPNE method, photo-essay.
\end{abstract}

Sumario: 1. Introducción, 2. Contexto y muestra, 3. Metodología, 4. Análisis, 4.1. Recogida de datos, 4.2. Selección de imágenes, 4.3. Análisis de datos y categorías emergentes, 5. Resultados. Posición básica de aprendizaje circular, 6. Conclusiones. Referencias.

\title{
1. Introducción
}

El objetivo de esta investigación consiste en visibilizar la relación entre cuerpo y espacio, en el ámbito educativo universitario en el que se desarrollan enseñanzas sobre percusión corporal con relación al método BAPNE (Romero Naranjo, 2008).

Las principales referencias teóricas que podemos reconocer en este trabajo de investigación son el método BAPNE y la obra visual de Isidro Blasco.

El método BAPNE tiene como finalidad el desarrollo de las inteligencias múltiples a través de la percusión corporal apoyándose en cinco disciplinas como son la biomecánica, la anatomía, la psicología, la neurociencia y la etnomusicología. Cada una de ellas establece unos parámetros concretos que ayudan a sistematizar todas las actividades teórico prácticas dando lugar al acrónimo BAPNE. La biomecánica nos ayuda a entender cómo se mueve el cuerpo humano en el espacio gracias a sus planos y ejes; la anatomía aporta los movimientos exactos para la ejercitación de estructuras óseas y musculares concretas; la psicología nos ayuda a emplear el movimiento desde el punto de vista terapéutico (Romero Naranjo, 2012b). Y por último, la etnomusicología nos ayuda a entender de qué manera se mueve el cuerpo en diferentes culturas cuyos patrones varían según etnias y continentes (Romero Naranjo, 2008). Estas cinco disciplinas nos ayudan a estructurar y sistematizar la metodología, pero son las inteligencias múltiples las que nos ofrecen las herramientas, las formas y la finalidad de cada actividad partiendo de las bases estipuladas por Gardner (1983). Es por ello, que el enfoque metodológico se ramifica desde ocho puntos de vista con el fin de desarrollar las inteligencias musical, corporal y cinética, espacial y visual, interpersonal, intrapersonal, naturalista, lingüística y matemática. 

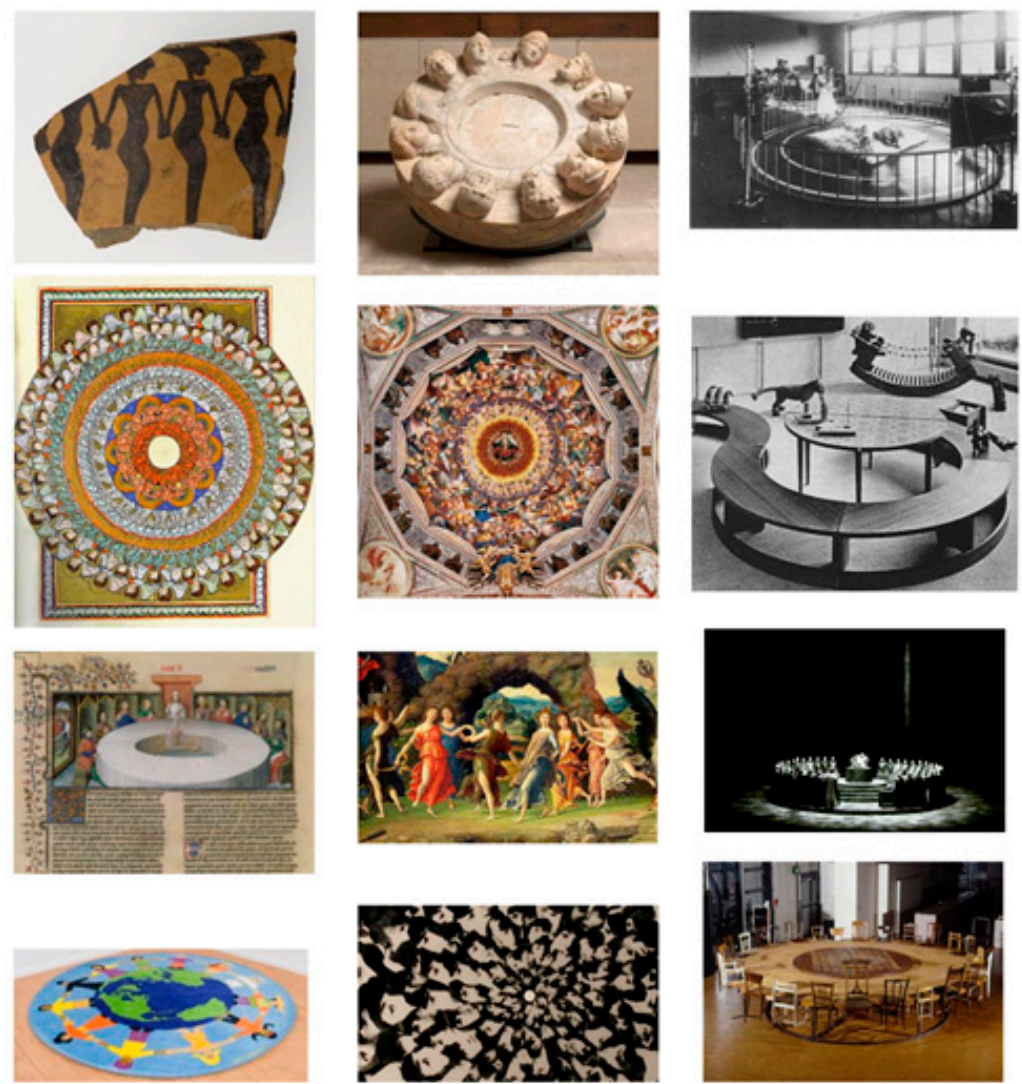

Figura 1. Foto-introducción formada por 12 citas visuales literales; de arriba abajo y de izquierda a derecha: [1] Ronda de músicos y bailarinas. Fragmento cerámico protohistórico Irán, 4000 a.C.: París, Musée du Louvre, inv. AO10935. [2] El altar astrológico proto-ecuménico con las doce divinidades del Olimpo y los signos del zodiaco procedente de la antigua colección Borghese, fechada en torno al 1 o 2 siglo d.C. (Gabies, época romana). París, Musée du Louvre, inv. MA666. [3] Jardín de infancia Baxa diseñado por Karel Pop, Praga (1935-1937). Fotografía, 30 x $60 \mathrm{~cm}$. Architectural Archive of the National Technical Museum, Praga. [4] Gaudenzio Ferrari, El concierto de los ángeles (Asunción de la Virgen), c. 1534-1538 Cúpula, santuario Madonna dei Miracoli, Saronno. [5] Gaudenzio Ferrari, El concierto de los ángeles (Asunción de la Virgen), c. 1534-1538 Cúpula, santuario Madonna dei Miracoli, Saronno. [6] Auke Komter, Muebles infantiles para Metz \& Co, 1938. Diversas medidas. Colección particular, Ámsterdam. [7] Los caballeros de la Mesa Redonda (Relato de Sir Lancelot/La Bastante de Saint Graal), s. XIV. París, Bibliothèque Nationale de France, Ms. Fr. 120, fol. 524 v. [8] Andrea Mantegna, Marte y Venus (detalle de El Parnaso), detalle: Danza circular de las ninfas apolíneas. París, Musée du Louvre, inv. 370. [9] Escenografía e iluminación circular de Wieland Wagner para la producción de Parsifal (Richard Wagner) en la reapertura del Festival de Bayreuth (1951). [10] Alfombra circular "multicultural" para clases de Eduación Primaria. Música e introducción a los Estudios Multiculturales: 2 metros de diámetro. Edusentials Ltd. (EUA). [11] Portada para un álbum de The Beattles, por Robert Freeman. Collage fotográfico, 1966. [12] La instalación Round Table del artista chino Chen Zhen (1955-2000), realizada en 1995 para la exposición "Dialogue de Paix" con ocasión del 50 aniversario de las Naciones Unidas: conjunto de 29 sillas originarias de los cinco continentes y procedentes de las diferentes clases sociales, encastradas en una mesa circular y suspendidas alrededor del suelo; un disco lleva una 
inscripción de un texto chino en el centro. París, Centre Pompidou, Musée National d'Art Moderne, Centre de création industrielle.

Desde el campo de las Artes Visuales es posible recurrir a múltiples referencias educativas basada en el aprendizaje circular de la música (ver figura 1), donde el cuerpo entra en relación con el espacio. Estas referencias artísticas de interés, nos permiten observar que a través de la música se pueden disolver las relaciones jerárquicas entre las personas mediante la figura circular. Es interesante extrapolar estas fórmulas históricoculturales de disolución jerárquica asociadas a la música, a los elementos pedagógicocognitivos.

En esta investigación, el modelo conceptual es la obra visual, tanto fotográfica como escultórica, de Isidro Blasco. Basarnos en la forma de hacer de este artista contemporáneo alicantino con residencia en Nueva York, nos permite construir a su manera la percepción óptica del espacio educativo. Nos facilita componer discursos visuales de las aulas donde se producen aprendizajes musicales relacionados con la percusión corporal.

Partiendo de la deformación óptica de nuestra mirada y de su actuación en la cristalización de la memoria, identifica ésta con la fotografia, mediante la seriación y posterior unión de fotografías realizadas en tiempos y espacios inmediatamente progresivos refleja la síntesis de la percepción en el transitar urbano. (Tejeda, 1992, p. 3).

De la misma forma en que se describe el modo de operar del artista nos interesa enfocar esta investigación. Nos concierne identificar con la fotografía la deformación óptica del investigador, uniendo la seriación de imágenes realizadas en tiempos y espacios inmediatamente progresivos, para reflejar la síntesis de la percepción en el transitar, en este caso, por el aula musical.

La investigación queda marcada por dos ejes. Por un lado existe una continua referencia visual a la obra de Isidro Blasco. Por otro lado se establecen paralelismos entre el objeto de estudio de esta investigación, el análisis espacial educativo, y los focos de interés desvelados por los críticos de arte respecto a la obra de este artista -a los que nos hemos referido mediante citas textuales-.

Al observar el aula de música deseamos investigar sobre los espacios ocupados por el grupo estudiantil. Pero también nos atrae profundizar sobre las zonas muertas, aquellos lugares abandonados donde no se sitúa ni el alumnado ni el profesorado, márgenes desechados, límites del interés, fronteras a partir de las cuales parece no darse el conocimiento, rincones no observados mientras se hace percusión corporal. El volumen que queda entre las personas y las cuatro paredes de la clase. Y al modo de Isidro Blasco al estudiar el espacio urbano y el volumen entre las edificaciones, y salvando las distancias, así estudiar nosotros el espacio educativo y el volumen intrapersonal. "Luego, a partir de las fotografías, y respetando las distorsiones que éstas producen, define el vacío, el volumen virtual, e irregular, que queda entre las casas" (Bonet, 1992, p. 8).

\section{Contexto y muestra}

El estudio se realiza gracias a la colaboración de los alumnos del Máster universitario en profesorado de educación secundaria (obligatoria, bachillerato y formación profesional) y enseñanzas artísticas, de idiomas y deportivas. Se desarrolla durante el curso académico 
2012-2013, en la Facultad de Educación de la Universidad de Alicante, en España.

La recogida de datos se lleva a cabo en el mes de enero de 2013, en dos de las últimas sesiones de la asignatura. La investigación se elabora gracias a la colaboración de los 27 alumnos matriculados en la asignatura obligatoria de "Percusión corporal e Inteligencias Múltiples - Método BAPNE”.

\section{Metodología}

La metodología seguida en este trabajo es la Investigación Educativa Basada en las Artes Visuales (Visual Arts Based Educational Research) (Marín, 2005; Marín y Roldán, 2008, 2009, 2010), que se englobaría dentro de la Investigación Educativa Basada en el Arte (Arts-Based Educational Research) (Eisner \& Barone, 2006).

Se propone además en esta investigación el cruce entre la disciplina musical y las artes visuales, lo que genera un nuevo enfoque. Tal y como consideran en sus disertaciones sobre la Investigación Educativa Basada en el Arte Sinner, Leggo, Irwin, Gouzouasis, \& Grauer (2006): "A/r/tography, and arts-based research in general, is fundamentally concerned with sharing lived experiences because collaboration represents a potential to include voices in research that may not otherwise be heard" (p. 1249).

Nos decantamos de entre los dos tipos de Investigaciones Fotográficas basadas en las Artes que define Roldán (2012), por aquella que como modelo de visualización "aplica los conocimientos fotográficos profesionales al estudio de nuevas situaciones que antes no habían sido fotografiadas" (p. 52). De manera que como instrumento se emplea un principal referente conceptual y metodológico: la obra del artista Isidro Blasco.

Escoger a un artista como referente teórico visual en una investigación educativa basada en las artes visuales es establecer relaciones formales y simbólicas con respecto a un precedente artístico, a la referencia de un autor. Las obras artísticas proponen ideas, procesos de pensamiento e intuiciones que pueden sostener a nivel conceptual, teórico y metodológico un estudio basado en ellas. (Pérez y Roldán, 2012, p. 4).

Decimos que en esta investigación Isidro es un referente a nivel conceptual porque el artista durante su trayectoria siempre ha trabajado sobre la idea del espacio construido y su ocupación, los lugares son de interés en el momento en que atañen a la forma en que las personas los habitan, y el modo en que condicionan a esas mismas personas en sus relaciones cotidianas.

Así, Blasco transforma lo espacial en táctil. Este sentido corpóreo de la visión, lo táctil convertido en forma física, ha sido una preocupación permanente en el trabajo de Blasco. Sus proyectos son espacios construidos que hacen referencia a las emociones y los recuerdos de lugares; las construcciones en sí han sido como esculturas parecidas a estancias, o intervenciones en forma de pantallas dentro de los espacios de galerías o museos. Evoca los muros, los suelos, techos y rincones de los lugares -o bien los interrumpe y los reinterpreta-como por medio del tacto y la memoria, más concretamente, por la unión de esas dos experiencias. (Cullen, 2003, p.9). 
A nivel metodológico también es un referente en esta investigación, tanto durante el proceso de indagación y recogida de datos, como durante el ensamblaje de las imágenes en la elaboración del discurso visual. Isidro Blasco se caracteriza porque sus trabajos "Son fotos fragmentadas, deconstruidas y reconstruidas fuera del plano, en todo caso instantáneas aún más esquivas que las tomadas por una cámara, aunque ahí esté el origen" (Costa, 2010, p.15). La construcción visual es ejecutada por el artista siempre por medio del collage. En el inicio de su trayectoria hacia 1992 uniendo imágenes fotográficas de forma sucesiva y sin superposiciones. Para ir evolucionando hacia formas más complejas y volumétricas que permiten reproducir la percepción del entorno envolvente. Alcanzando en la actualidad soluciones escultóricas que permiten ir superponiendo en sucesivas capas, fotográficas o audiovisuales, secuencias espaciales y temporales.

En nuestra investigación extrapolaremos, a las dos dimensiones limitantes del formato revista, esta concepción tridimensional empleada por el artista en los últimos tiempos.

\section{Análisis}

\subsection{Recogida de datos}

La toma de fotografías se realiza durante el transcurso de las últimas semanas de clase. En estos momentos el alumnado ya es capaz de desarrollar una amplia gama de ejercicios de percusión corporal diferentes, interesantes para la recogida de datos. Además el nivel de los alumnos permite la presencia de un agente extraño realizando una observación directa (Huerta, 2010), tomando fotografías sin perjudicar en el proceso de aprendizaje musical.

\subsection{Selección de imágenes}

A las sesiones de recogida de datos les sucede su descarga en el ordenador para un primer visionado. Así como la selección de fotografías bajo criterios estéticos y especialmente estilísticos acordes con el referente conceptual de Isidro Blasco.

\subsection{Análisis de datos y categorías emergentes}

En la siguiente fase se clasifican las imágenes conforme a los ejercicios de percusión con que se corresponden y atendiendo a la distribución del alumnado en el espacio. Según las posiciones básicas de aprendizaje de esta disciplina descritas por Romero Naranjo (2012a) hallamos: "círculo, círculos concéntricos, semicírculo, cuarteto, sexteto, octeto, parejas, dos filas (sin movimiento), dos filas (con movimiento), entrecruzados, dos filas (con movimiento enfrentado), espejo" (p. 24).

En el momento de análisis de las fotografías seleccionadas emergen evidencias respecto a la importancia de las relaciones entre espacio y educandos en las disposiciones circulares. Es por ello que se escoge esta categoría de disposiciones 
circulares para profundizar sobre ellas en este trabajo de investigación. Estas evidencias deben ser expuestas en los resultados de forma que se consiga transmitir la importancia del círculo como posición básica de aprendizaje, pero especialmente por sus imbricaciones con el espacio, con el movimiento (Vicente Nicolás, 2010, 2012) y en las relaciones interpersonales.

\section{Resultados. Posición básica de aprendizaje circular}

Isidro Blasco es un artista que nos ofrece como referentes la percepción óptica del espacio, ya sea tanto el espacio público como el privado, el espacio urbano como el íntimo y hogareño, el espacio lleno y el vacío, el espacio positivo y el negativo. Dirige la mirada del observador hacia los rincones más insospechados, hacia los lugares donde habitualmente no reposa la atención. Le otorga a los huecos y silencios la importancia escultórica merecida. Y guía el ritmo del "voyeur" ralentizando la captación de los detalles y las secuencias temporales. Según Torrente (2003) en la pasión constructiva de Isidro Blasco "hay una curiosidad que se centra en el análisis espacial" (p. 21).

$\mathrm{Y}$ es precisamente este tipo de análisis espacial el que perseguimos con esta investigación, aquel que nos permita aproximarnos a la intimidad de un aula cuando en ella se desarrollan procesos de enseñanza-aprendizaje musicales. Especialmente con la disciplina del body percussion y concretamente con el Método BAPNE (Romero Naranjo, 2012b), que concibe la disposición de los individuos en el espacio como parte fundamental de su imbricación en el desarrollo de la inteligencia visual y espacial, interpersonal e intrapersonal. Lo cual desarrolla habilidades no siempre fomentadas en el aula de forma general en otras materias no artísticas. Y de igual forma desarrolla estas habilidades para su repercusión tanto dentro del aula como fuera de la misma, a corto y largo plazo.

De pronto, lo que parecía un discurrir continuo del tiempo y la mirada, podía mostrarse fraccionado sobre una mesa, como las famosas fotos de Muybridge que inspirarian directamente los futurismos, los cubismos, a todo lo de-reconstructivo en general. Y el collage... Isidro Blasco nació bastante más hacia acá y su mirada retoma aquella de la instantánea sumada a otra visión nueva que subjetiviza de nuevo, pero de otra forma (Costa, 2010, p. 16).

Desde el punto de vista pedagógico, abogamos en las disciplinas artísticas por un tipo de enseñanza inclusiva, y no exclusiva. Un tipo de docencia en la que deben generarse lazos de colaboración en contraposición a la competitividad. Favorecer estos aspectos depende en gran medida de las dinámicas generadas en el aula, la forma en que los individuos se miran, se tocan, se situan o posicionan. Como profesores debemos tomar conciencia de las variables que componen las posiciones básicas de aprendizaje en el aula, en este caso en la musical.

La forma de trabajo circular implica por un lado que todos los estudiantes estén arropados, por otro lado genera empatía al multiplicar los ejes de comunicación visual entre individuos. Esta figura se encuentra en el polo opuesto a la disposición tradicional que sitúa al alumnado en filas frente a quien posee la autoridad del 
conocimiento, más si cabe cuando el profesor se encuentra subido a una tarima. Según Doménech y Gómez (2003) existe una relación entre las creencias psicopedagógicas implícitas del profesor y el modelo de enseñanza derivado con el tipo de organización física del aula propuesto por el mismo. La disposición vertical reflejaría un modelo de enseñanza centrado en el profesor y en el producto.

Existen otras disposiciones intermedias, en el sentido de no ser tan extremas en la información que transmiten respecto a la relación docente-discente como pueden ser:

- El semicírculo. Lo encontramos por ejemplo en asambleas de aula y anfiteatros. En éste modelo ya se establece una jerarquía al posicionar de un lado al alumnado formando un semicírculo que observa al profesor. En esta postura el docente no forma parte del grupo, está parcialmente integrado pero mantiene las distancias académicas.

- Múltiples pequeños círculos. Se halla en los trabajos por rincones o para alcanzar pequeños consensos. Fomenta el buen trabajo cooperativo a pequeña escala. Sin embargo el profesor aunque no se integra porque se mantiene al margen, se encuentra disponible como apoyo a todos ellos.

- Filas enfrentadas. Es común en debates, eskudantzas, procesos de selección tribales (los Massai) o cuando se quieren generar enfrentamientos. El profesor puede situarse de forma integrada o a parte como moderador y árbitro del proceso de aprendizaje.

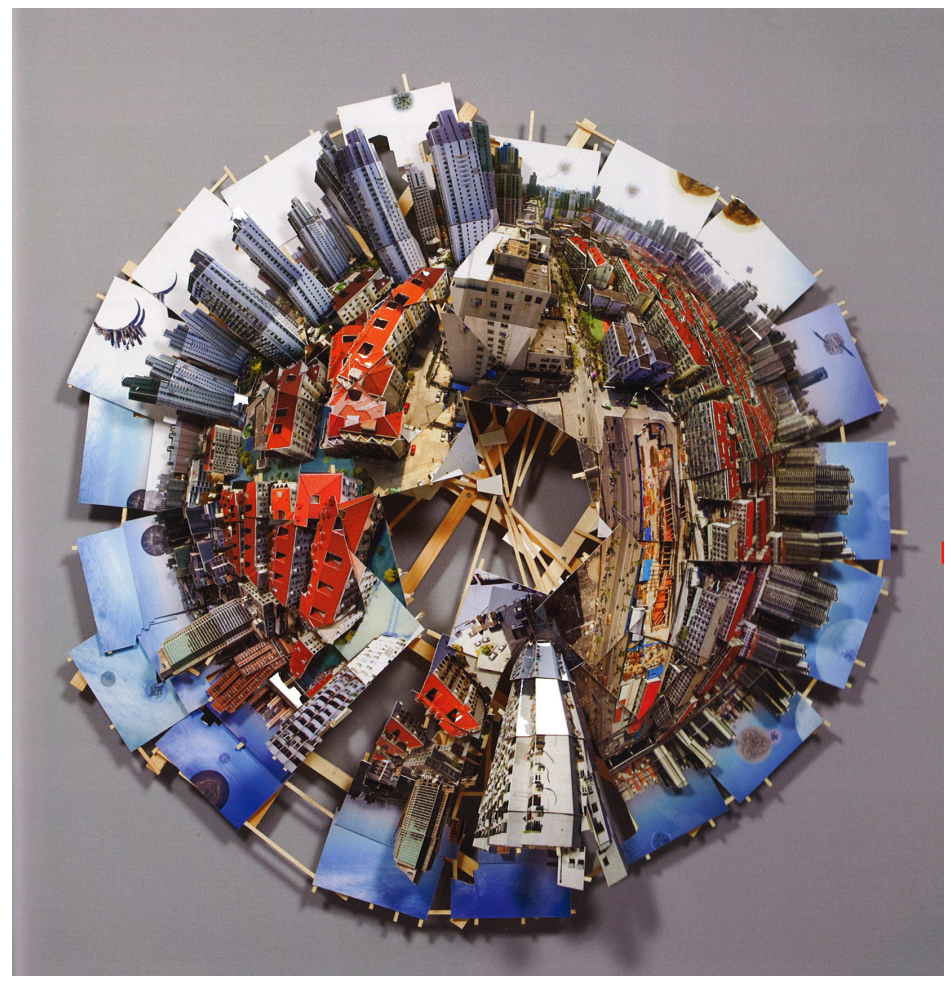

Figura 2. "Shanghai como lo ven sus habitantes, como centro del universo conocido. La ciudad rodeada de meros satélites" (Blasco, 2010, p. 64). 


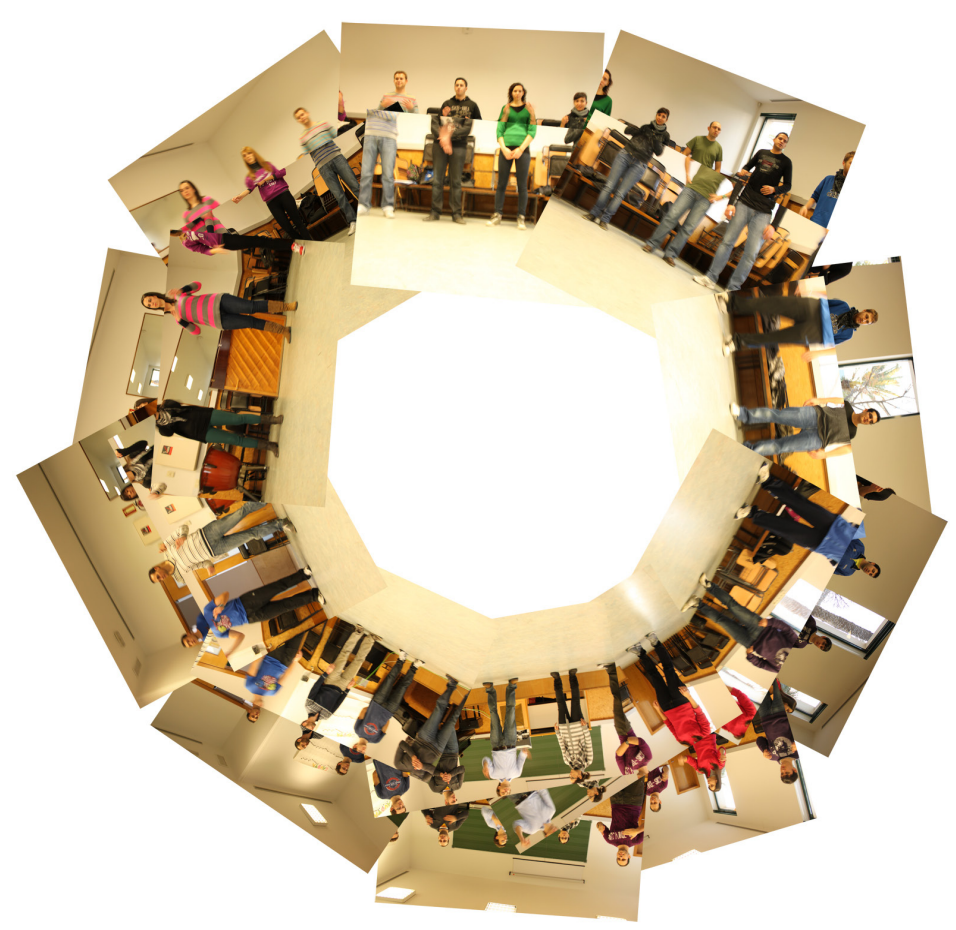

Figura 3. Percusión corporal de pie en dos círculos concéntricos (enero de 2012). Facultad de Educación de la Universidad de Alicante, España.

El círculo como el área contenida por la circunferencia que configuran las personas al situarse unas próximas a otras, es entendido aquí como lugar de encuentro educativo. Sabemos del término como forma de interacción social en sus diversas acepciones. Todo ello participa de la idea de esta figura que es inclusiva, integradora, que convoca, reúne y resulta intermediadora de los procesos de enseñanza. Desde el punto de vista didáctico el profesor percibe que no se enseña, ni se aprende de la misma manera cuando uno se sitúa tras una mesa, que cuando permanece de pie, o sentado, o en posiciones que determinan jerarquías. El círculo favorece un aprendizaje horizontal, donde se cruzan las miradas de estudiantes y profesorado. El círculo posibilita una comunicación no verbal, al permitir observar las caras, cuerpo y gestualidad de todos los participantes y no exclusivamente la del docente. Por todo ello el círculo es la disposición en el aula que mejor representa el modelo de enseñanza-aprendizaje por el que abogamos en las disciplinas artísticas. Por supuesto no monopolizando por completo el transcurso de las sesiones, pero sí haciendo acto de presencia en una gran parte de las dinámicas empleadas.

Desde el punto de vista etnográfico la forma de trabajo circular es muy propia de las culturas tribales porque fomenta la participación y el diálogo de forma comunitaria en todos sus ámbitos. Desde la perspectiva etnomusicológica ese diálogo conlleva una serie de gestos y miradas que permiten interactuar, alternar e improvisar entre sus ejecutantes sin mediar palabra (López Cano, 2005). Esta forma de interactuar 
grupalmente conlleva una carga energética que se acumula en el centro y revierte de forma centrífuga hacia los participantes; lo cual genera a nivel cerebral una mayor producción de la hormona oxitocina -generadora de seguridad y confianza principalmente-. Si a todo esto le unimos un trabajo cinético, donde estamos siempre en movimiento y mayoritariamente de pie, se desarrolla entre los participantes un mayor nivel de atención focal y sostenida. Son diversos los autores que justifican esta forma de proceder desde el punto de vista etnográfico, destacando las publicaciones de Ortiz (1951), Blacking (1995), Rouget (1985) y Arom (2004) entre otros tantos. Esta forma de trabajo genera indirectamente un grado de implicación cada vez mayor y si incluimos un nivel de repetición continuo, conlleva al trance en muchísimas culturas.

En las culturas tribales que van del sur hacia el centro de África podemos observar que toda interación grupal y comunitaria siempre gira en torno a la forma circular. Conforme subimos del sur hacia el norte de Africa las disposiciones van modificándose. En el sur de África las mujeres y los hombres están mezclados en un mismo círculo, cantándo todos en unísono, pero ellas en su registro grave, nunca en el natural. En el norte de África, como es el caso de los bereberes, suelen tender a romper la forma circular, dividiéndose en dos grupos, uno para cada sexo, donde las mujeres cantan en su registro natural y son los hombres los que agudizan en determinados cantos la voz para ponerse en los niveles de ellas, Kubik (1988). La interpretación que se deduce de ello está en que conforme subimos el continente africano la forma de interacción grupal circular se va diluyendo para pasar a una formación dividida y más jerarquica. Quizás se da paso a una formación que genera más la competitividad y el trabajo individual. En el método BAPNE con la intención de realizar un trabajo que no fomente la competitividad ni la jerarquía se responde a formas círculares para fomentar el mejor resultado académico posible.

Esto es lo que sabemos desde la perspectiva didáctica y etnográfica de la posición básica de aprendizaje circular en las relaciones interpersonales. ¿Pero qué sabemos desde la perspectiva visual? ¿Qué ocurre cuando dirigimos nuestra atención hacia las personas y cuando lo hacemos al espacio que queda entre ellas? ¿Tomamos conciencia de los elementos y mobiliario que invaden el espacio educativo? ¿Cómo interfieren en la distribución espacial las formas del aula, su estructura y rincones? ¿Qué visualizamos si cambiamos la altura de la mirada y el encuadre que tradicionalmente emplean profesor y alumnado? ¿Cómo prestar atención a lo que permanece estático y a la vez a cuanto se mueve durante el aprendizaje musical? 


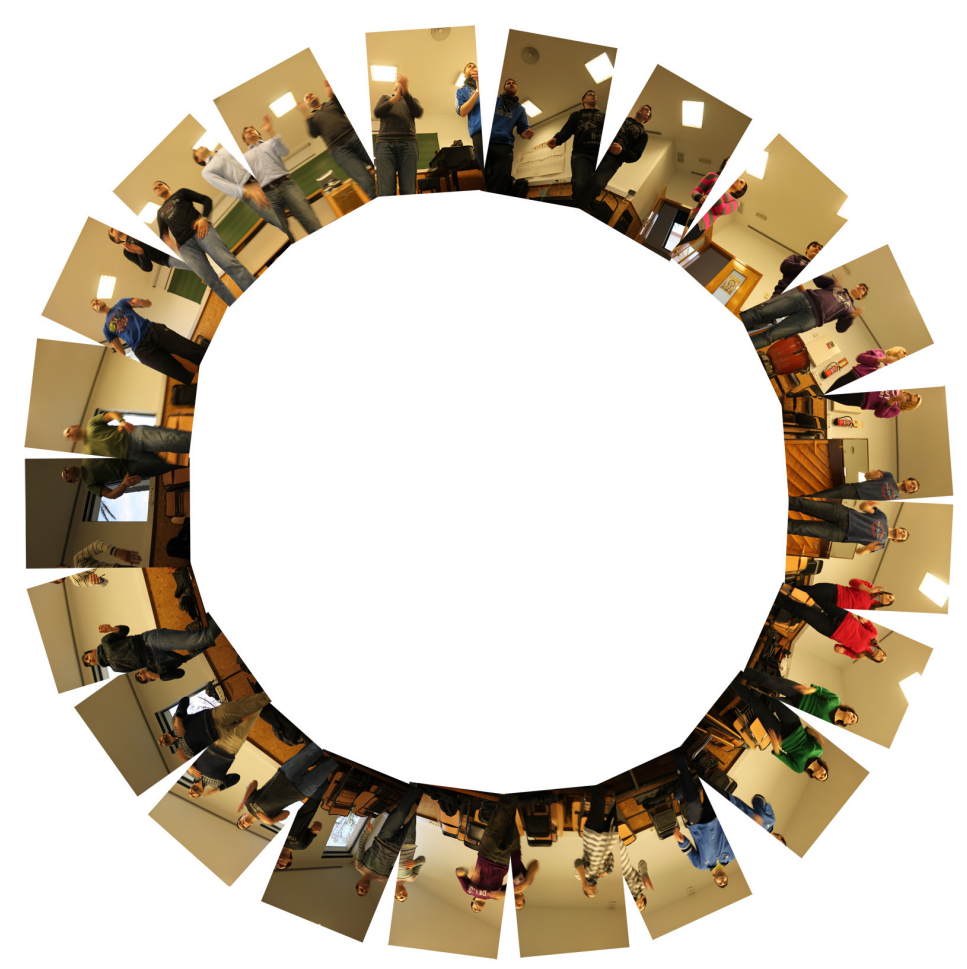

Figura 4. Percusión corporal de pie en círculo (enero de 2012). Facultad de Educación de la Universidad de Alicante, España.

Atendiendo a los conocimientos fotográficos hallados en la obra "Shanghai planet 2009” de Isidro Blasco se ofrecen modelos de visualización que ponen de manifiesto alguno o varios de los recursos empleados por el artista, pero no todos a la vez. Pues no se trata de reproducir una obra del artista con temática diferente. Lo que se persigue es poner en práctica, en función del problema a estudiar, las formas de construir que este artista de reconocido prestigio ya ha validado. También se barajan algunos recursos que en otras obras artísticas ha empleado el artista a lo largo de su trayectoria. 


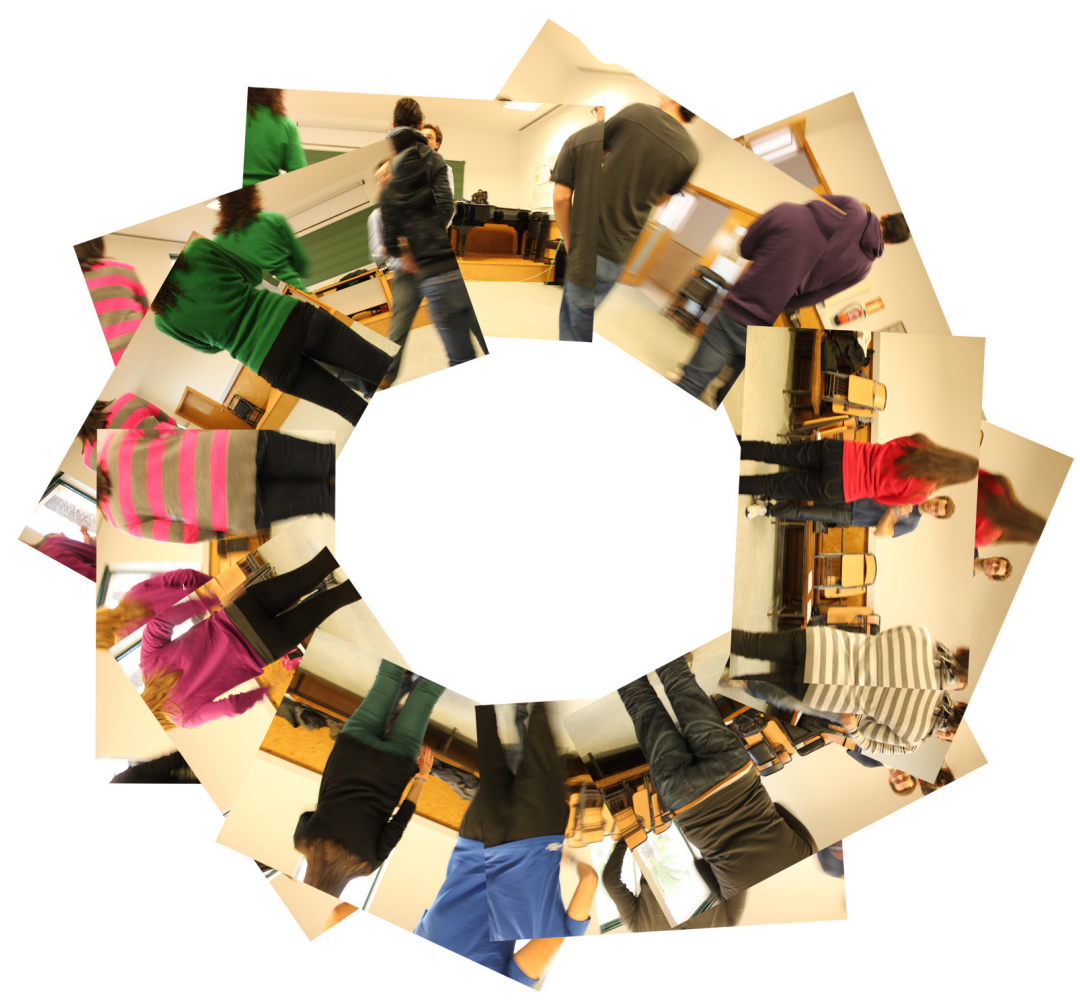

Figura 5. Percusión corporal de pie en círculo (enero de 2012). Facultad de Educación de la Universidad de Alicante, España.

Así, como mínimo común múltiplo de nuestros resultados, se generan en todos los collages estructuras circulares en las que las fotografías en color se distribuyen de forma radial, por ser el modelo compositivo que mejor describe la posición básica de aprendizaje circular empleada en la percusión corporal. En este sentido se constata que las fotografías utilizadas en esta investigación sirven como modelo de visualización que expresa un razonamiento visual de análisis del espacio "aula de música" en relación con el cuerpo. Pero para enfatizar unas u otras relaciones del análisis se refuerza el uso de unos u otros recursos, tal y como puede observarse en los resultados. 


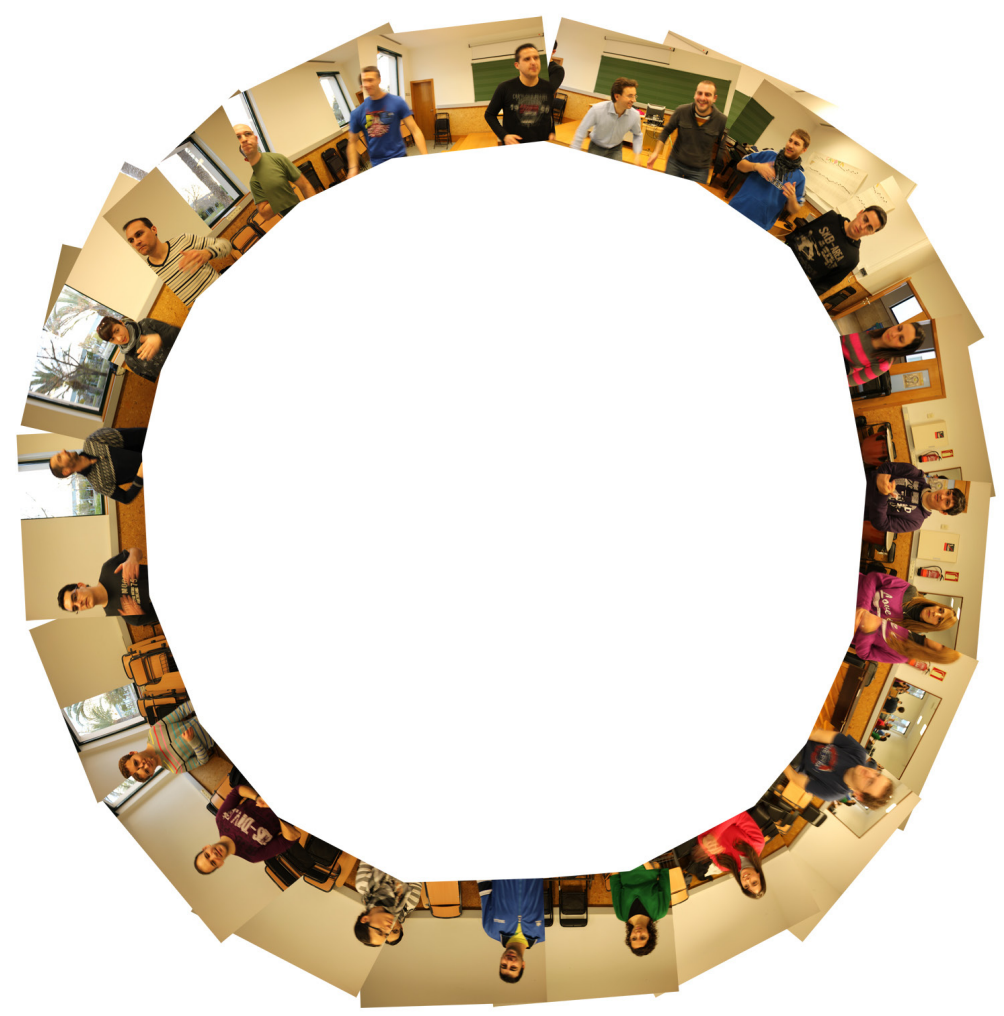

Figura 6. Percusión corporal de pie en círculo (enero de 2012). Facultad de Educación de la Universidad de Alicante, España.

El docente de música que desea realizar su investigación sobre los procesos resultantes de su propia práctica, o de las prácticas educativas de un grupo de profesores, dispone de numerosos entornos en los que documentar sus acciones, especialmente en el tramo del trabajo de campo. Para nosotros el concepto de "aula de música" es amplio, y comprende varios escenarios. (Huerta, 2010, p. 19)

De forma que en unas propuestas se insiste en la importancia de la superposición de estampas como sugerencia del solape temporal. Mientras que en otros casos se emplea el recurso de repetir algún elemento de la representación que ha variado su posición o postura durante el análisis espacial. En otros casos se apela a la importancia de los lugares ausentes de imagen, espacios vacíos. También se estudia la posibilidad de encuadrar el volumen que queda por encima de los elementos representados (Blasco aire sobre edificios, nosotros aire sobre cabezas de estudiantes). O enfocar tanto lo que ocurre en el interior como en el exterior del espacio analizado (exterior de la vivienda, exterior del círculo). Incluso otorgar relevancia a elementos simbólicos periféricos (satélites en la obra de Blasco), que circundando el elemento principal objeto de representación, le dan al conjunto el matiz conceptual. 


\section{Conclusiones}

Las referencias artísticas son testimonios de las diversas culturas. A lo largo del tiempo las Artes Visuales han reflejado las tradiciones, conductas y formas de entender las relaciones interpersonales del hombre, en relación con la música. Estas referencias nos permiten extrapolar elementos pedagógico-cognitivos pues corresponden a fórmulas histórico-culturales de disolución jerárquica asociadas a la música.

La obra "Shanghai planet 2009" del artista Isidro Blasco, supone un referente artístico contemporáneo, clave como estructura estilística para la Investigación Educativa Basada en las Artes Visuales, como instrumento metodológico. Debería considerarse como un modelo de composición de múltiples fotografías, que por su estructura tridimensional, radial, circular y en $360^{\circ}$ aporta las siguientes oportunidades:

- Vertebra de forma idónea la descripción global de un problema.

- Aporta un enfoque volumétrico al análisis espacial.

- Contextualiza los elementos representados.

- Interrelaciona los elementos caracterizados como parte de un conjunto.

- Visualiza los espacios ocupados mediante fotografías y los vacíos mediante huecos ausentes de representación.

- Conecta el espacio con el transcurso del tiempo.

- Superpone elementos analizados visualmente.

- Genera una mirada radial desde un centro geométrico en el que sitúa el espectador.

- Mediante los satélites introduce a los elementos figurativos otros de carácter simbólico.

Hallar las estructuras estilísticas acordes con el problema de estudio resulta fundamental para expresar las hipótesis, resultados y conclusiones de una Investigación Educativa Basada en las Artes Visuales. En nuestro caso el modelo de Isidro Blasco ha sido clave para las visualizaciones de la posición básica de aprendizaje circular en el Método BAPNE de percusión corporal y su relación con el espacio.

\section{Referencias}

Arom, S. (2004). African polyphony and polyrhythm: musical structure and methodology. Cambridge: University Press.

Blacking, J. (1995). Venda children's songs. Chicago: The University Chicago Press. (Ed. Orig. 1967).

Blasco, I. (2010). Shanghai planet 2009, 1x1x1,8 m, escultura, C-print, madera y cartón de museo. En I. Blasco, Isidro Blasco. Aquí huidizo [17 marzo-16 mayo, 2010, Sala de Exposiciones Alcalá 31$]$ (p. 64). Madrid: Vicepresidencia, Conserjería de Cultura y Deporte y Portavocía del Gobierno de la Comunidad de Madrid y Diputación Provincial de Huesca.

Bonet, J. M. (1992). Textos de catálogo. En I. Blasco, Isidro Blasco, en el laberinto. Isidro Blasco:[exposición 5-30 mayo, Palacio Gravina] (pp. 7-9). Alicante: Instituto de cultura "Juan Gil-Albert". 
Costa, J. M. (2010). Cuando despertamos.... En I. Blasco, Isidro Blasco. Aquí huidizo [17 marzo-16 mayo, 2010, Sala de Exposiciones Alcalá 31] (pp.13-19). Madrid: Vicepresidencia, Conserjería de Cultura y Deporte y Portavocía del Gobierno de la Comunidad de Madrid y Diputación Provincial de Huesca.

Cullen, D. (2003). La mirada de la madona. En I. Blasco, Isidro Blasco. La vida duradera de las cosas [13 abril-19 junio, 2003, Patio Herreriano Museo de Arte Contemporáneo Español] (pp. 7-19). Valladolid: Patio Herreriano Museo de Arte Contemporáneo Español.

Eisner, W. E. \& Barone, T. (2006). Arts-Based Educational Research. En J. L. Green, G. Camilli y P. B. Elmore (Eds.), Handbook of complementary methods in education research (pp. 95-109). Mahwah, New Jersey: AERA.

Gardner, H. (1983). Frames of mind: The theory of multiple intelligences. Nueva York: Basic Books.

Huerta, R. (2010). Investigación por estudios de caso en el aula de música. Actas del I Congreso Internacional de Investigación en Música. Valencia: ISEACV.

Kubik, G. (1988). Zum Verstehen afrikanischer musik. Leipzig: Reclam Verlag.

Lopez Cano, R. (2005). Los cuerpos de la música: Introducción al dossier Música, cuerpo y cognición. Revista Transcultural de Música, 9. Recuperado el 15 de enero de 2006, de http://www.sibetrans.com/trans/a175/los-cuerpos-de-la-musicaintroduccion-al-dossier-musica-cuerpo-y-cognicion

Marín, R. (2005). La "Investigación Educativa Basada en las Artes Visuales" o "Arteinvestigación educativa". En R. Marín (Ed.), Investigación en Educación Artística (pp. 223-274). Granada: Editorial Universidad de.

Marín, R. y Roldán, J. (2008). Imágenes de las miradas en el museo. Un fotoensayo descriptivo- interpretativo a partir de H. Daumier. En R. de la Calle y R. Huerta (Eds.), Mentes Sensibles. Investigar en Educación y Museos. (pp. 97-108). València: Publicacions de la Universitat de.

Marín, R. y Roldán, J. (2009). Proyecciones, tatuajes y otras intervenciones en las obras del museo (Un fotoensayo a partir de T. Struth). Arte, Individuo y Sociedad, 21, 99-106.

Marín, R. y Roldán, J. (2010). Photo essays and photographs in visual arts-based educational research. International Journal of Education through Art, 6 (1), 7-23.

Ortiz, F. (1951). Los Bailes y el teatro de los negros en el folklore de Cuba. La Habana: Ministerio de Educación, Dirección de Cultura.

Pérez, G. y Roldán, J. (2012). La identidad visual del docente universitario: Un ensayo visual a partir de David Hockney. En M. D. Callejón y M. I. Moreno (Eds.) Arte, educación y cultura. Aportaciones desde la periferia, (178, pp. 1-10). Jaén: Ilustre Colegio Oficial de Doctores y Licenciados en Bellas Artes de Andalucía.

Roldán, J. (2012). En R. Marín y J. Roldán (Eds.), Metodologías artísticas de investigación en educación (pp. 40-63). Málaga: Ediciones Algibe.

Romero Naranjo, F. J. (2008). Percusión corporal en diferentes culturas. Música y Educación 76 (4). 46-97.

Romero Naranjo, F. J. (2012a). Didáctica de la percusión corporal. Fundamentación teórico-práctica (1). Barcelona: Body music Body percussion Press. (Ed. Orig. 2010). 
Romero Naranjo, F. J. (2012b). Percusión corporal y lateralidad. Método BAPNE. Música y Educación 91(3), 30-51.

Rouget, G. (1985). Music and trance. A theory of the Relations between Music and Possesion. Chicago: The University Chicago Press.

Sinner, A., Leggo, C., Irwin, R. L., Gouzouasis, P. \& Grauer, K. (2006). Arts-Based Educational Research dissertations: reviewing the practices of new scholars. Canadian Journal of Education 29 (4), 1223-1270.

Tejeda, I. (1992). Introducción. En I. Blasco, Isidro Blasco:[exposición 5-30 mayo, 1992, Palacio Gravina] (p.3). Alicante: Instituto de cultura "Juan Gil-Albert".

Torrente, V. (2003). Inventariando la memoria. En I. Blasco, Isidro Blasco. La vida duradera de las cosas [13 abril-19 junio, 2003, Patio Herreriano Museo de Arte Contemporáneo Español] (pp. 21-31). Valladolid: Patio Herreriano Museo de Arte Contemporáneo Español.

Vicente Nicolás, G. (2010). Las actividades de movimiento en el aula de música: una aproximación a través de los libros de texto. Educatio siglo XXI 28(1), 209-226.

Vicente Nicolás, G. (2012). Música y Movimiento. Variaciones sobre un mismo tema. Eufonía Graó 54(1),74-81. 